\title{
DESENVOLVIMENTO COMO MISSÃO
}

\section{Luiz Carlos Bresser-Pereira}

FGV-EESP
Celso Furtado foi o maior dos economistas brasileiros, e o mais reconhecido internacionalmente. Escreveu obras fundamentais, como Formação econômica do Brasil (1959) e Desenvolvimento e subdesenvolvimento (1961), que o inscreveram entre os grandes economistas mundiais que nos anos 1940 e 1950 criaram a nova teoria do desenvolvimento. Teve uma participação decisiva, juntamente com Raúl Prebisch, na Cepal, na formulação da teoria econômica estruturalista latino-americana, e colaborou com o grupo de intelectuais do I seb no estabelecimento das bases teóricas da política nacional-desenvolvimentista que está atrás do grande desenvolvimento do Brasil e da América Latina entre 1930 e $1980 .^{1}$ Elaborou uma teoria original do subdesenvolvimento, distinguindo-o do mero atraso. Fundou a Sudene, elaborando então um plano inovador para corrigir as diferenças regionais no Brasil. Ministro do Planejamento em um momento de absoluta crise política, em 1963, produziu um plano austero de estabilização, o Plano Trienal, que não foi implementado. Exilado, continuou no exterior seu trabalho teórico e sua análise crítica da economia brasileira - o que não 0 impediu de também apresentar, em 1968, na Câmara dos Deputados, nas vésperas do Ato Institucional $\mathrm{n} 05$, um projeto de retomada do desenvolvimento com distribuição de renda que, em seguida, constituiu Um projeto para o Brasil. De volta ao Brasil, depois de uma passagem pelo governo Sarney, onde já não Ihe atribuíram funções na área econômica, foi aos poucos se transformando na consciência crítica das novas administrações econômicas, que, a partir de 1990, impuseram ao Brasil o credo neoliberal. Foi um período em que Furtado foi quase esquecido. Para muitos, era um economista do passado, um nacionalista no tempo da globalização e do globalismo, um desenvolvimentista nos tempos dos mercados livres e da ortodoxia convencional. Entretanto, mais recentemente, diante do fracasso da ideologia neoliberal e globalista em restabel ecer o equilíbrio macroeconômico no país e retomar o desenvolvimento, os brasileiros voltaram a lembrar-se de Furtado, e começaram as homenagens e o reconhecimento. Eu próprio organizei, com José Márcio Rego, um livro em sua homenagem, que várias vezes ele me disse ter sido a melhor homenagem que recebeu. ${ }^{2}$

No entanto, Celso Furtado morreu frustrado. Sua grande paixão foi sempre o Brasil, e por isso mesmo a decepção foi grande. Um homem que pôs todas as suas esperanças na sua terra, viu, aos poucos, elas serem desfeitas, primeiro com o regime militar de 64, depois, em 1985/86, com 0 colapso do pacto democrático-popular das "Diretas Já" em estabilizar a economia e retomar o desenvolvimento, e, finalmente, nestes últimos dois anos, ao verificar que o governo que apoiara com entusiasmo traíra suas promessas de campanha. Mas morreu lutando. 0 nível da taxa de juros, em particular, o deixava indignado. Uma taxa que é a contrapartida da taxa de câmbio baixa, val orizada, é uma forma de assegurar o subsídio pelo Estado às elites rentistas.

Mas não seriam todas essas críticas simples manifestações de "populismo", como sugerem os defensores da ortodoxia convencional dominante? Embora criticando a ortodoxia convencional com vigor, porque via nela interesses contrários aos do país, Celso Furtado jamais aceitou a solução falsamente keynesiana de incorrer em déficit público para promover o crescimento. Sua luta no Brasil contra as taxas de juros decididas pelo Banco Central visava precisamente proteger o Tesouro nacional e viabilizar a recuperação da poupança pública e dos investimentos na infra-estrutura. Por isso, inclusive, opunha-se ao conceito de superávit primário, que esconde 0 efeito dos juros sobre 0 déficit público. Como resultado de sua análise, Cel so Furtado estava convencido de que as classes beneficiadas pela concentração de renda não se revelam à altura de seu papel de elites. Ao copiarem os padrões de consumo norte-americanos, não poupam para investir, e endividam o país no exterior. Ao defenderem a política monetária, aumentam sua renda financeira às custas do Tesouro nacio- 
nal. Celso, entretanto, não desesperava jamais. Ele sabia que para construir uma nação não bastam trabal hadores e técnicos de classe média. Também são necessários empresários.

\section{EM BUSCA DE NOVO MODELO}

Em seu último livro, Em busca denovo modelo (São Paulo: Paz eTerra, 2002), F urtado novamente nos obrigou a refletir de forma crítica sobre os problemas do Brasil. Ele volta às raízes do desenvolvimento econômico: a revolução capitalista e a revolução científica. A interação entre esses dois processos deve ser buscada, de um Iado, na intuição de Galileu de que a natureza seria racional e poderia ser reduzida a esquemas geométricos, e de outro, no processo de acumulação capitalista, que torna a racional idade instrumental dominante. N esse processo, porém, a industrialização tardia de países como o Brasil é muito diferente da que ocorreu nos países hoje desenvolvidos, porque enquanto nestes a inovação e a difusão se combinam para responder às próprias necessidades das sociedades, naqueles a difusão é marcada pela tentativa de imitação, por parte das elites - as classes al tas e as médias -, dos padrões de consumo do centro. Essa reprodução dos padrões de consumo vai continuar a determinar hoje as duas tendências centrais das economias periféricas, que estão presentes em sua análise desde os anos 1950. A primeira é a propensão ao endividamento externo e a segunda, a propensão à concentração social da renda. Ambos os processos têm como matriz a alta propensão a consumir das elites brasileiras em sua ansiedade em reproduzir o consumo central.

Comparando o Brasil com a Índia, em um momento em que a Índia não se tornara ainda um centro de aten- ções em todo o mundo pelo seu êxito econômico, ele nos apresenta dados poderosos em favor do seu argumento. Embora a Índia tenha uma renda por habitante que éum quinto da brasileira, sua taxa de poupança é consideravelmente maior do que a do Brasil. Como se explica isso? Porque no Brasil a renda é muito mais concentrada nas classes altas e médias do que na Índia. N este país, os 20\% mais ricos controlam uma renda quatro vezes maior do que os $20 \%$ mais pobres, enquanto no Brasil essa relação é 32 vezes maior! A busca da reprodução dos padrões norte-americanos de consumo está na raiz tanto da concentração de renda como da baixa taxa de poupança. As duas se combinam porque, para um consumo de bens e serviços de preço relativamente el evado, se faz necessária a concentração social da renda. $\mathrm{N}$ a desigual dade que caracteriza a economia brasileira, não existe, porém, apenas um problema de injustiça; há também uma questão de desenvolvimento. As classes beneficiadas pela concentração de renda não se revelam à altura de seu papel de elites. Ao copiarem os padrões norte-americanos de consumo, não poupam para investir, e endividam 0 país no exterior. A acusação de prática do populismo econômico, que essas classes usam para atacar os políticos populares, é indevida porque é 0 consumo delas e não o dos pobres que leva ao déficit público e, principalmente, ao "populismo cambial": a vaIorização artificial do câmbio, em nome do combate à inflação, para facilitar o consumo de bens e serviços com considerável componente importado. Não são os pobres que adquirem bens importados, nem que viajam para o exterior.

Assim, Celso Furtado concentra sua análise no consumo das elites. Enquanto as elites cafeeiras do oeste paulista e, mais tarde, as elites indus- triais e tecnocráticas, que surgiram entre 1930 e 1950, foram notáveis em promover o desenvolvimento nacional, as elites de hoje, alienadas, não têm projeto de nação. Diante desse fato, ao mesmo tempo em que Furtado salienta o papel dos intelectuais em darem racionalidade à estratégia e à política econômica, afirma que "o ponto de partida do processo de reconstrução que temos de enfrentar deverá ser uma participação maior do povo no processo de decisão" (ibid., p. 36). A questão central é saber se temos ou não possibilidade de preservar nossa identidade cultural e nacional. 0 que os governos dos países ricosfazem é defender o capital e o trabalho nacionais, ou seja, suas empresas nacionais. O Brasil não tem outra alternativa senão fazer o mesmo.

\section{MÉTODO}

Celso Furtado via no desenvolvimento econômico do Brasil uma missão, um projeto de vida. Para realizar essa tarefa tão ambiciosa quanto frustrante - porque, afinal, o Brasil ficou aquém de suas grandes esperanças -, Celso usou do método e da paixão. No método ele foi rigoroso, mas isso não o impediu de encarar com paixão seu objeto de estudo, que foi sempre também um projeto republicano de vida: o desenvolvimento do Brasil. Um dos livros de Carlos Drummond de Andrade se chama A paixão medida. Esse oxímoro, que 0 grande poeta usou com tanta propriedade, é útil para entendermos Celso Furtado. A paixão é forte, tornando sua obra e sua vida prenhes de energia e de vontade de transformação econômica e política, mas é uma paixão medida, que pesa custos e tradeoffs - como é próprio dos bons economistas -, e não esquece as restrições políticas. 
Furtado é um economista da teoria do desenvolvimento e da análise da econômica brasileira. N essas duas especialidades ele pensou sempre de forma independente, e usou principalmente o método histórico em vez do lógico-dedutivo. Sua capacidade de inferência e de dedução é poderosa, mas ele parte sempre da observação da realidade, evita partir de pressupostos gerais sobre o comportamento humano e procura, a partir dessa realidade e do seu movimento histórico, inferir a teoria.

Celso Furtado éum economista do desenvolvimento. Fez parte do grupo dos "pioneiros" da teoria moderna do desenvolvimento, ao lado de Rosenstein-Rondan, Prebisch, Singer, Lewis, N urkse, Myrdall e Hirschman. Suas contribuições teóricas se concentraram no entendimento do processo de desenvolvimento e de subdesenvolvimento econômico. E para isso veremos que usou, antes de mais nada, o método que é mais adequado ao estudo do desenvolvimento: 0 histórico-dedutivo, ou seja, o método que parte da observação da realidade econômica, social e política, que é uma realidade histórica, para, em seguida, generalizar.

A marca principal em sua trajetória intelectual é a da independência teórica. A teoria econômica que utiliza, ele a aprendeu com os clássicos, entre os quais David Ricardo e Karl Marx têm um papel de destaque, juntamente com J ohn M. Keynes. Pouco deve aos neoclássicos. Entretanto, não significa que Furtado seja um marxista ou um keynesiano. Ele aprendeu com os clássicos e com Keynes, mas seu pensamento éindependente, e ele sempre fez questão absoluta dessa independência. Está identificado com o estruturalismo e com o nacionaldesenvolvimentismo latino-americano, na medida em que ele foi um dos seus fundadores. 0 estrutural ismo foi

uma doutrina econômica influente na América Latina nos anos 1950 e 1960 porque oferecia uma interpretação para o subdesenvolvimento dos países que, em meados do século XX, faziam a transição de formas pré-capitalistas ou mercantis para o capitalismo industrial. 0 nacional-desenvolvimentismo apresentava a seus dirigentes uma estratégia coerente de desenvolvimento com base em um acordo nacional.

A independência teórica do pensamento de Furtado permite que el e use as teorias que julgar relevantes para resolver os problemas de interpretação dos fatos econômico que tenha pela frente. 0 marxismo é para ele importante na medida em que oferece uma visão poderosa da história e do capitalismo, mas a contribuição de $M$ arx à teoria econômica é menor. Ao descrever seu aprendizado do marxismo, na França, no final dos anos 1940, ele nos diz:

\begin{abstract}
A formidável vista que descortina Marx sobre a gênese da história moderna não deixa indiferente nenhuma mente curiosa. Já a contribuição no campo da economia parecia de menos peso, para quem estava familiarizado com o pensamento de Ricardo e conhecia a economia moderna. (FURTADO, C. A fantasia organizada. Rio de Janeiro: Editora Paz e Terra, 1985. p. 31).
\end{abstract}

Sua preocupação com a independência do seu pensamento apareceu com clareza quando decidiu deixar o Rio de Janeiro e ir trabal har em Santiago, na Cepal, que acabara de ser criada. Naquele momento a Cepal era ainda um projeto vazio. Furtado não conhecia Prebisch, que ainda não formulara sua visão do desenvolvimento da América Latina. Não obstante, ele decide partir, para "escapar ao cerco, ganhar um horizonte aberto, ainda que para vagar em busca de uma Atlântida perdida". Faz essa afirmação em A fantasia organizada (p. 50), e em seguida manifesta seu acordo com Sartre e sua filosofia da responsabilidade, segundo a qual, se fundássemos nossas verdadeiras escol has apenas na razão, não haveria escolhas, tudo estaria predeterminado.

A criatividade será uma das bases da sua independência intelectual em relação às ortodoxias. Gérard Lebrun, escrevendo sobre A fantasia organizada, observa: "É o odor de heterodoxia que torna esse livro ainda mais fascinante e faz de Celso Furtado um grande escritor, assim como um pensador". ${ }^{3} 0$ heterodoxo não nega os pressupostos mais gerais da sua ciência, mas recusa subordinar seu pensamento ao dominante. A direita e os economistas convencionais insistem em dar à heterodoxia uma conotação negativa, identificando-a com populismo econômico, mas, na verdade, inovar em teoria e em análise econômica envolve quase sempre alguma heterodoxia. Ser heterodoxo é desenvolver teorias novas, muitas vezes a partir da identificação de fatos históricos novos que modificam um determinado quadro econômico e social e tornam as teorias preexistentes inadequadas. Quando Celso Furtado optou por usar prioritariamente o método histórico, e quando se tornou um dos dois fundadores do estruturalismo latino-americano, Furtado estava optando pela heterodoxia e pela independência de pensamento.

U ma forma por meio da qual Furtado evidenciou sua independência de pensar foi se manter fiel ao método histórico-dedutivo, não obstante a ortodoxia tenha se tornado, nos anos oitenta, cada vez mais hipotético-dedutiva. Sem dúvida, usou com abundância sua capacidade de inferência lógica, mas sempre o fez a partir dos 
fatos históricos e da sua tendência a se repetirem, não a partir de uma pressuposição de comportamento racional. Enquanto historiador econômico era natural que utilizasse prioritariamente o método históricoindutivo, mas isso também é verdade quando ele assume o papel de teórico do desenvolvimento e do subdesenvolvimento. Assim, não estou sugerindo que Furtado tenha pertencido à escola historicista al emã de List, ou ao institucionalismo americano de Veblen. Essas escolas se caracterizaram pela recusa da teoria econômica, e pela busca casuística da análise dos fatos econômicos, enquanto Furtado usa a teoria econômica disponível e procura fazê-la avançar na compreensão do desenvolvimento econômico.

Ao adotar o método histórico, Furtado se aproxima da dialética de Hegel e do materialismo histórico de Marx, embora deles se mantenha independente, principalmente por dar à vontade humana um papel maior. "A importância da dialética para a compreensão dos processos históricos deriva do fato de que a história [...] não pode ser reconstituída a partir da multiplicidade de fenômenos que a integra". Entretanto, por meio dela o homem "intui no processo histórico aquela visão sintética capaz de dar unidade à multiplicidade". M arx adotou esse princípio dial ético de forma audaciosa ao dividir a sociedade em infra e superestrutura, e em duas classes sociais. Essa estratégia,

[...] teve extraordinária importância como ponto de partida para o estudo da dinâmica social [...] Contudo, é necessário reconhecer que a esse nível de generalidade quase nenhum valor apresenta um modeIo analítico como instrumento de orientação prática. E o objetivo da ciência - conclui ele, deixando transparecer o pragmatismo que sempre o orientou - é produzir

guias para a ação prática.

Retirei esses trechos de Dialética do desenvolvimento (Rio de Janeiro: Fundo de Cultura, 1964. p. 14-15 e 22), livro que Furtado escreve em meio à crise do governo Goulart, depois de se demitir do Ministério Extraordinário do Planejamento, e de novo dirigindo apenas a Superintendência da Sudene. Entre seus livros, esse é talvez aquele que dele mereceu maior atenção: um resumo completo (FURTADO, C. A fantasia desfeita. Rio de Janeiro: Paz e Terra, 1989. p. 182190). Em A fantasia desfeita, Furtado afirma com clareza que um dos seus objetivos foi delimitar o emprego do marxismo e da dialética na análise do desenvolvimento. E ao fazê-lo, ele reafirma seu compromisso com o rigor do método científico.

O segundo objetivo do livro Dialética do desenvol vimento seria precisar o alcance da dialética, que voltara à voga com a Crítica de Sartre, deixando claro queutilizá-la não nos dispensava de aplicar com rigor o método científico na abordagem dos problemas sociais. Entretanto, adotar o método científico com rigor não significa adotar modelos analíticos apoiados na suposição do equilíbrio estável, como é tão comum na economia. Para a análise do desenvolvimento precisamos de model os dinâmicos, do tipo do "princípio cumulativo" proposto por Myrdal. Mais amplamente, conclui Furtado que,

Por mais que tenhamos avançado na construção de modelos, cabe reconhecer que sempre partimos para sua construção de al gumas hipóteses intuitivas sobre o comportamento do processo histórico como um todo. E a mais geral dessas hipóteses é a que nos proporciona a dialética, pela qual o histórico é aquilo que necessariamente se encontra em desenvolvimento. A idéia do desenvolvimento surge como uma hipótese ordenadora do processo histórico - como "síntese de várias determinações, unidade da multiplicidade", na expressão de Marx - a partir da qual é possível realizar um esforço eficaz de identificação de relações entre fatores e de seleção desses fatores com vistas à reconstrução desse processo através de um modelo analítico (FURTADO, C. Dialética do desenvolvimento. Rio de Janeiro: Fundo de Cultura, 1964).

Com esse texto exemplar - que mostra a el egância e capacidade de síntese de Furtado para expressar seu pensamento - ele deixa claro o que entende pelo caráter histórico e dial ético do método científico que adota. Eu poderia ter iniciado com essa citação a análise de seu método, mas preferi concluir minha análise com suas palavras.

\section{PAIXÃO}

$\mathrm{Na}$ forma pela qual Celso Furtado trabalhou com a ciência econômica não há apenas método rigoroso, há também paixão. Há grandes esperanças e a frustração correspondente. Geralmente a razão e a emoção são vistas em oposição, o que é uma forma equivocada de compreender 0 processo do pensamento. Os grandes cientistas foram com muita freqüência pessoas apaixonadas pelo seu trabalho, por sua pesquisa. Os economistas que foram real mente grandes dificilmente deixaram de se apaixonar não apenas por sua ciência, mas também pelos resultados dela. Alguns se apaixonaram pela conquista da estabilidade econômica, outros por uma distribuição de renda mais 
justa e a maioria pelo desenvolvimento de seu país.

A paixão de Furtado foi o desenvolvimento do Brasil. Paixão alimentada pela crença de que esse desenvolvimento estava ao alcance do seu país no momento histórico em que se forma como economista, no final dos anos 1940. A Segunda Guerra Mundial havia terminado. Novas teorias do desenvolvimento econômico estavam surgindo. Uma grande esperança se desenhava diante dos olhos do jovem paraibano que acabara de obter seu doutorado em economia na França, em 1948: o Brasil, que já vinha se industrializando de forma acelerada, superaria os desequilíbrios estruturais de sua economia e, com a ajuda da teoria econômica e do planejamento econômico, alcançaria 0 estágio de país desenvolvido.

Só essa paixão - a paixão pela idéia do desenvolvimento do Brasil - explica a força de seu pensamento, especialmente nos seus primeiros livros, desde seu primeiro artigo fundamental sobre a economia brasileira, "Características gerais da economia brasileira" ${ }^{4}$ e de seu primeiro livro, A economia brasileira, de 1954, até Dialética do desenvol vimento, de 1964, escrito em um momento em que as esperanças começavam a se esgarçar com a iminência da crise. Todos esses trabalhos possuem uma força teórica e um poder de análise que não derivam apenas da criatividade, da cultura ampla, da independência de pensamento e do uso preferencial do método histórico-indutivo. Estão claramente relacionados com um projeto de vida que se identifica com o projeto do desenvolvimento. Em Os ares do mundo (Rio de Janeiro: Paz e Terra, 1991, p. 63) ele deixa claro que seu projeto de vida estava diretamente relacionado com a convicção, que formou no final dos anos 1940, de que "uma feliz conjuntura internacional
- conseqüência da grande depressão dos anos 1930 e do conflito mundial dos anos 1940 - abrira uma brecha pela qual quiçá pudéssemos nos esgueirar para obter uma mudança qualitativa em nossa história".

Essa mudança qual itativa era a industrialização e o desenvolvimento do Brasil. Mas Furtado, relembrando 1964, quando chega exilado ao Chile, já nesse ano se convencera de que, embora "o intelectual tenha de próprio a capacidade sem limites de inventar-se razões para viver", seu projeto de vida, que se baseara na existência daquela brecha, era, afinal, "uma ilusão que [...] agora se desvanecia" (ibid., p. 45 e 63). A fantasia estava desfeita. A esperança fora grande, mas a desilusão e a frustração são maiores ainda. Frustração e desilusão que vão se expressar no seu livro seguinte, Subdesenvolvimento e estagnação na América Latina (Rio de Janeiro: Civilização Brasileira, 1966), um livro denso e pessimista, que se revela equivocado em seguida, na medida em que as economias latino-americanas entram em novo ciclo de desenvolvimento. 0 equívoco, entretanto, irá afinal se revelar relativo acerto. 0 ciclo de desenvolvimento, que então se iniciava, foi artificialmente financiado pela dívida externa, uma dívida que tornou as economias latinoamericanas prisioneiras do capital financeiro internacional e, afinal, as levou à grande crise dos anos $1980 \mathrm{e}$ à quase-estagnação que até hoje perdura. Digo "relativo acerto" porque a tese central do livro, que tem influência de Marx e de Keynes, continua a me parecer mal colocada. A estagnação ou o desenvolvimento a taxas muito baixas seria devido, de um lado, ao aumento da relação capital - trabaIho, em função do caráter capital-intensivo dos investimentos, e à diminuição da relação produto-capital decorrente em grande parte desse mesmo caráter capital-intensivo da tecnologia adotada; e, de outro, desua destinação para bens de consumo duráveis. Assim a produtividade do capital estaria em queda. Essa teoria subestima, a meu ver, a natureza do progresso técnico, que não é apenas poupador de trabalho, mas pode ser também poupador de capital, ou seja, pode e tende cada vez mais a ser um progresso técnico que aumenta a eficiência do capital. ${ }^{5}$

Em Subdesenvolvimento e estagnação da América Latina já aparece a idéia de que a concentração de renda estava impedindo o funcionamento do círculo virtuoso do capitalismo, o processo por meio do qual o aumento da produtividade aumenta os salários e a demanda agregada. Em dois livros, Furtado responde indiretamente a seus críticos. Em Análise do modelo brasileiro (Rio de Janeiro: Civilização Brasileira, 1972) incorpora ao seu pensamento, com grande elegância e precisão, a teoria da nova-dependência que surgira da crítica a seus trabal hos. 0 que não o impede de, em 0 mito do desenvolvimento (Rio de Janeiro: Paz e Terra, 1974), reafirmar com clareza sua tese sobre a insuficiência de consumo a longo prazo. A concentração da renda da classe média para cima não resolvia o problema da demanda no processo de desenvolvimento. Em suas palavras,

Minha hipótese básica é que o sistema não tem sido capaz de produzir espontaneamente o perfil de demanda capaz de assegurar uma taxa estável de crescimento, equeo crescimento a longo prazo depende de ações exógenas do governo [...] Se bem que esses dois grupos (as grandes empresas e as minorias modernizadas) têm interesses convergentes, o sistema não está estruturalmente capacitado para gerar o tipo de expansão de demanda requeri- 
do para assegurar sua expansão (FURTADO, C. 0 mito do desenvolvimento. Rio de Janeiro: Paz e Terra, 1974).

Ora, essa tese, como mostrou Keynes ao fazer a crítica da Lei de Say, é válida a curto prazo, para explicar o ciclo econômico. E só é válida a longo prazo na medida em que a taxa de desenvolvimento alcançada nesse prazo depende da manutenção da demanda em constante tensão com a oferta a curto prazo. 0 novo modelo de desenvolvimento tecnoburocrático-capitalista que se instaurava então no Brasil, produzindo um subdesenvolvimento industrializado, afinal fracassou, mas não foi por um problema de insuficiência de demanda, e sim pelo excesso irresponsável de endividamento externo. A esperança ainda vai se manifestar para Celso Furtado quando, em 1968, antes do A to Institucional $n^{\circ} 5$, que instaurou de vez a ditadura no país, eleé convidado pela Câmara dos Deputados para apresentar sua visão do que poderia ser feito. Ele não resiste, e escreve U m projeto para o Brasil (Rio de Janeiro: Saga, 1968), onde faz uma proposta para retomar o desenvol vimento a partir de um substancial aumento da carga tributária e da poupança pública. Entretanto, se há o retorno da esperança a recusa em aceitar a dependência e 0 subdesenvolvimento - , o pessimismo continua o mesmo. A análise pessimista da situação do Brasil era consistente com a de Subdesenvolvimento e estagnação da América Latina, tanto que as primeiras críticas a essa perspectiva foram realizadas a partir da análise desses dois livros, mostrando que a retomada do desenvolvimento brasileiro ocorria graças à concentração de renda da classe média para cima, que criava demanda para os bens de consumo de luxo.

A paixão otimista que alimentava a ação se transformava agora na grande frustração de quem percebe que não apenas deixara de poder influenciar diretamente os destinos do país, mas que o próprio país perdera capacidade de desenvolvimento endógeno. A teoria econômica que agora usava se tornava discutível na medida em que envolvia um duplo pessimismo: primeiro, em relação à capacidade de os sistemas econômicos subdesenvolvidos terem progresso técnico capital-intensivo, mas poupador de capital ou pelo menos neutro (não envolvendo, portanto, redução da produtividade do capital); e, segundo, em relação à capacidade de a oferta criar demanda a longo prazo. Seu pessimismo aparece na citação seguinte, tirada de 0 s ares do mundo, na qual ele relembra seus primeiros meses em Santiago após o exílio:

Não me fugia a idéia de que a história é um processo aberto, sendo ingenuidade imaginar que o futuro está cabalmente contido no passado eno presente. Mas, quando toda mudança relevante é fruto da interveniência de fatores externos, estamos confinados ao quadro da estrita dependência [...] As tendências que se manifestavam no Brasil levavam a pensar que as mudanças significativas já não seriam fruto da ação de fatores endógenos. (FURTADO, C. Os ares do mundo. Rio de Janeiro: Paz e Terra, 1991, p. 63).

Nos anos 1970 Furtado volta a participar ativamente de reuniões internacionais por meio das quais os países em desenvolvimento reclamavam "uma nova divisão internacional do trabalho". Durante um certo tempo o movimento foi bem-sucedido, mas, com a crise da dívida externa e a onda neoliberal que toma conta de Washington e do mundo a partir do início dos anos 1980, também aquele projeto não deu os frutos esperados. Para a América Latina começava a grande crise dos anos 1980. E diante dela, a paixão de Celso Furtado volta com força, na forma de indignação. Seus livros N ão à recessão e ao desemprego (São Paulo: Paz eTerra, 1983) e Brasil: a construção interrompida (São Paulo: Paz e Terra, 1992) são uma prova dessa indignação. ${ }^{6}$

O retorno do exílio e a participação no governo Sarney, como ministro da Cultura, não Ihe permitem mudar os sentimentos de frustração e indignação. ${ }^{7}$ M as em 1999, recuperada a estabilização, e quando há indicações de alguma retomada do desenvolvimento, a esperança lhe volta, embora ele se mantenha um forte crítico da política econômica do governo Fernando Henrique Cardoso. Em seu penúltimo livro, 0 longo amanhecer (Rio de Janeiro: Paz e Terra, 1999), ele assinala de forma forte sua desilusão, ao afirmar que em nenhum momento de nossa história foi tão grande a distância entre o que somos e o que esperávamos ser. Volta a fazer a crítica da globalização, que por meio do endividamento externo irresponsável levou o país à grande crise. Entretanto, observa que não é a própria globalização e seu descontrole, mas a forma pela qual nossas elites têm reagido a ela, a responsável pela nossa incapacidade de retomar o desenvolvimento, optando por adotar sem críticas uma política econômica que privilegia as empresas transnacionais, cuja racionalidade pode ser captada apenas no quadro de um sistema de forças que transcende os interesses específicos dos países que o integram. Exemplo dessa alienação é a proposta pela própria Cepal, em fevereiro de 1999, de dolarização das economias latino-americanas, processo que já estaria avançado, segundo a organização internacional.

Em uma curta intervenção em se- 
minário realizado em São Paulo em sua homenagem, "Reflexões sobre a crise brasileira" ${ }^{8}$ sua crítica não atinge apenas os governos, mas mais amplamente as elites brasileiras. Ele repudia especialmente as "explicações ( para a quase-estagnação) que pretendem ignorar as responsabilidades morais das elites". Observa, diante de palavras favoráveis à dolarização que então circulavam na imprensa - hoje provavel mente esquecidas frente à crise que a dolarização provocou na Argentina -, que "se submergirmos à dolarização, estaremos regredindo ao estatuto semicolonial". Mas, como em seu último livro, nesse artigo vemos que a esperança, afinal, está de volta. No livro, no qual há uma seção cujo título é "Que fazer?", ele salienta a necessidade de reverter o processo de concentração de renda, de investir em capital humano e, principal mente, de enfrentar o problema da gl obal ização com o fortalecimento do Estado nacional, que é "o instrumento privilegiado para enfrentar os problemas estruturais".

$\mathrm{Na}$ breve intervenção ele volta a afirmar uma de suas teses centrais: a importância da criatividade política. Despeço-me desta pensata deixando uma frase de Furtado, proferida nessa intervenção, para que o leitor reflita a respeito: "Somente a criatividade política impulsionada pela vontade coletiva poderá produzir a superação do impasse" (p. 4).

\section{NOTAS}

${ }^{1}$ Veja em BRESSER-PEREIRA, L. C. O conceito de desenvolvimento do Iseb rediscutido. Dados - Revista de Ciências Sociais, Rio de Janeiro, v. 47, n. 1, p. 49-84, 2004. Celso Furtado não pertenceu ao grupo do Iseb, mas esteve muito próximo dele, tendo feito duas conferências nessa instituição, publicadas pelo Iseb como pequenos livros: Perspectivas da economia brasileira. Rio de Janeiro: Iseb, 1958; eA operação N ordeste. Rio de Janeiro: Iseb, 1959.

${ }^{2}$ BRESSER-PEREIRA, L. C.; REGO, J. M. (O rgs.). A grande esperança em Celso Furtado. São Paulo: 34, 2001. A presente pensata se baseia, em parte, no artigo que escrevi para esse livro, "M étodo e paixão em Celso Furtado".
${ }^{3}$ LEBRUN , G. Os anos de aprendizado. São PauIo: Jornal da Tarde, 7 de setembro, 1985.

${ }^{4}$ Revista de Economia Brasileira, v. 4, n. 1, 1950.

${ }^{5}$ Veja em BRESSER-PEREIRA, L. C. Lucro, acumulação e crise. São Paulo: Brasiliense, 1986.

${ }^{6} \mathrm{No}$ intervalo entre esses dois livros ele escreveu seus três notáveis livros autobiográficos já mencionados: A fantasia organizada (1985), A fantasia desfeita (1989) e Os ares do mundo (1991).

\begin{abstract}
${ }^{7}$ Em 1984 Celso Furtado publica uma coletânea de ensaios com o título Cultura e desenvolvimento em época de crise, cujo tema central continua ser a crise da economia brasileira, mas que deve ter inspirado o presidente José Sarney a convidá-lo para o Ministério da Cultura. Fui então seu colega de ministério, entre abril e dezembro de 1987, quando ocupei o Ministério da Fazenda. Sua preocupação era enorme diante do fracasso do governo democrático em enfrentar a crise, que acabou aprofundando-a. Tão grande quanto seu sentimento de impotência diante dos fatos, situado que estava em um ministério que lhe permitiu me dar um apoio decisivo quando necessitei, mas que não lhe permitia mudar os rumos da economia brasileira. Afinal, minha passagem pelo governo foi breve, e também eu não consegui estabilizar a economia brasileira.

${ }^{8}$ Revista de Economia Política, v. 20, n. 4, p. 3-7, 2000.
\end{abstract}

\section{Pensata convidada. A provada em 20.03.2005.}

\section{Luiz C arlos Bresser-Pereira}

Professor da FGV-EESP. Doutor e livre-docente em economia pela USP.

Interesses de pesquisa nas áreas de teoria econômica e desenvolvimento, teoria política e desenvolvimento.

E-mail: bresser@fgvsp.br

Endereço: Rua Araripina, 132, Jd. Guedala, São Paulo - SP, 05603-030. 